\title{
ANALISIS KADAR PEMANIS BUATAN (SAKARIN DAN SIKLAMAT) PADA MINUMAN TEH KEMASAN BOTOL YANG BEREDAR DI MINIMARKET KOTA MAKASSAR
}

\author{
Rahmawati ${ }^{1)}$ \\ 1) Akademi Analis Kesehatan Muhammadiyah Makassar \\ Alamat Korespondensi: rahmawatiamma60@gmail.com
}

\begin{abstract}
Abstrak
Pemanis buatan merupakan suatu zat yang dapat menimbulkan rasa manis atau zat yang dapat memberikan kalori lebih rendah dari pada gula dan mempunyai struktur kimia yang berbeda dengan struktur kimia gula alami. Telah dilakukan pemeriksaan terhadap pemanis buatan sakarin maupun siklamat yang terdapat pada minuman teh kemasan botol yang beredar di Minimarket Kota Makassar. Sampel yang digunakan sebanyak 10 sampel, yang terdiri dari 10 merek dalam kemasan. Metode pemeriksaan yang meliputi pemeriksaan secara kualitatif dan pemeriksaan secara kuantitatif. Pemeriksaan ini dilakukan di Laboratorium Kimia Analisis Makanan dan Minuman Akademi Analis Kesehatan Muhammadiyah Makassar. Hasil pemeriksaan yang dilakukan terhadap 10 sampel minuman teh kemasan botol yang beredar di Minimarket Kota Makassar diperoleh 1 sampel yang mengandung pemanis buatan sakarin dan 9 sampel yang mengandung pemanis buatan siklamat.
\end{abstract}

Kata Kunci: Sakarin, Siklamat, dan Teh Kemasan

\section{PENDAHULUAN}

Tanaman teh pertama kali masuk ke Indonesia tahun 1684, berupa biji teh dari Jepang yang ditanam sebagai tanaman hias. Dalam perkembangannya, industri teh di indonesia mengalami pasang surut sesuai perkembangan situasi pasar dunia maupun Indonesia. Teh memiliki potensi untuk memenuhi kebutuhan manusia akan klorin dan flour.

Tanaman teh termasuk genus Camellia yang memiliki sekitar 82 species, terutama tersebar di kawasan Asia Tenggara pada garis lintang $30^{\circ}$ sebelah utara maupun selatan khatulistiwa. Selain tanaman teh (Camellia sinensis (L.) O. Kuntze) yang dikonsumsi sebagai minuman penyegar, genus Cammelia ini juga mencakup banyak jenis tanaman hias.

Hasil penelitian menunjukkan bahwa teh, di samping sebagai bahan minuman, sifat antiseptiknya dapat menjaga kesehatan mulut dan gigi, tenggorokan menjaga keseimbangan mikroflora sistem pencernaan, dan meningkatkan penyerapan kalsium untuk pertumbuhan tulang (Herawati W, 2013).

Kesehatan merupakan hal yang paling berharga bagi manusia, namun kita sering mengabaikannya. Kesadaran pentingnya menjaga kesehatan tersebut biasanya timbul ketika kita mengalami penyakit tertentu. Dalam kehidupan sehari-hari, sebenarnya yang termudah dan tersulit untuk menjaga kesehatan adalah memperhatikan asupan makan dan minum.

Makanan dan minuman jajanan sudah menjadi bagian yang tidak terpisahkan dari kehidupan masyarakat baik diperkotaan maupun dipedesaan. Konsumsi masyarakat diperkirakan terus meningkat mengingat makin terbatasnya waktu anggota keluarga untuk mengolah makanan sendiri. Keunggulan makanan dan minuman jajanan adalah mudah dan murah didapat, serta cita rasanya yang enak dan cocok dengan selera kebanyakan masyarakat. Meskipun makanan dan minuman memiliki keunggulan tersebut, ternyata memiliki keunggulan-keunggulan tersebut, ternyata makanan dan minuman 
tersebut masih berisiko terhadap kesehatan karena penanganannya sering tidak higenis, yang memungkinkan makanan dan minuman jajanan terkontaminasi oleh mikroba beracun maupun bahan tambahan makanan (BTM) yang tidak diizinkan.

Deputi Bidang Pengawasan Keamanan Pangan dan Bahan Berbahaya Badan Pengawasan Obat dan Makanan (POM) RI Dedi Fardiaz mengungkapkan, diindonesia masih banyak masalah terkait dengan menggunakan pemanis buatan. Meski sudah ada ketentuan batas maksimun yang diizinkan, penggunaan pemanis buatan masih sering digunakan semena-mena melebihi batas maksimun yang diperbolehkan.

Meningkatnya pemakaian pemanis buatan tersebut perlu dilihat dampaknya, mengingat pemanis buatan seperti siklamat dan sakarin dapat menimbulkan gangguan kesehatan apabila dikonsumsi secara berlebih diantaranya tumor pada otak, multiple sklerosis, epilepsi, sindrom kelelahan kronis, parkinson, lupus, alzheimer, cacat mental, limfoma, kelainan pada kelahiran anak, dan bahkan diabetes (Hanny W, 2010).

Berdasarkan uraian tersebut, maka peneliti melakukan penelitian Analisis Kadar Pemanis Buatan (Sakarin dan Siklamat) Pada Minuman Teh Kemasan Botol yang Beredar di Minimarket Kota Makassar.

\section{METODE PENELITIAN}

\section{Alat dan Bahan}

Alat yang digunakan yaitu gelas ukur, beker glas, labu pemisah, labu ukur, cawan porselen, hotplate, water bath, pipet ukur, pipet tetes, erlenmeyer, corong pemisah, biuret, tabung reaksi, rak tabung reaksi, bold pipet.

Bahan yang digunakan yaitu Minuman Teh Kemasan, Residu (5ml), Larutan $\mathrm{H}_{2} \mathrm{SO}_{4(\mathrm{p})}$, Larutan eter $(50 \mathrm{ml})$, Aquadest (10ml), Larutan K. Na Tartrat $\left(\mathrm{C}_{4} \mathrm{H}_{4} \mathrm{KNaO}_{6} .4 \mathrm{H}_{2} \mathrm{O}\right) 3 \%(0,5 \mathrm{ml}), 5$ tetes larutan $\mathrm{NaNO}_{2} 10 \%, \mathrm{HCl} 3 \mathrm{~N}, \mathrm{HCl} 4 \mathrm{~N}$, Indikator PP, Indikator Brom Thymol Blue, $\mathrm{KBr}, \mathrm{HCl}(\mathrm{p})$, Asam Oksalat $\left(\mathrm{H}_{2} \mathrm{C}_{2} \mathrm{O}_{4}\right)$, Asam Sulfanilat $\left(\mathrm{C}_{6} \mathrm{H}_{7} \mathrm{NO}_{3} \mathrm{~S}\right)$, Amoniak, Methyl Blue.

\section{Prosedur Penelitian}

Analisis Kualitatif

Sampel $100 \mathrm{ml}$ diasamkan dengan larutan $\mathrm{H}_{2} \mathrm{SO}_{4}$, dipisahkan sampel dengan lapisan eter yang berbentuk residu, kemudian ditambahkan $10 \mathrm{ml}$ aquades. Setelah itu, dibagi menjadi 2 (dua) bagian, satu bagian untuk pemeriksaan sakarin (bagian I) dan bagian yang lain (bagian II) untuk pemeriksaan siklamat. Bagian I dan II diperiksa kandungan pemanisnya secara kualitatif yaitu :

\section{Bagian I (Pemeriksaan Sakarin)}

Menambahkan 0,5 ml larutan K. Na Tartrat 3\% ke dalam residu, kemudian ditambahkan 0,5 $\mathrm{ml}$ Nessler dan dikocok. Memasukkan ke dalam tabung reaksi dan diamati warna dan endapan yang terbentuk.

\section{Bagian II (Pemeriksaan Siklamat)}

Residu ditambahkan 5 tetes larutan $\mathrm{NaNO}_{2} 10 \%$, Lalu ditambahkan 5 tetes larutan $\mathrm{BaCl}_{2}$ 10\%. Dimasukkan ke dalam water bath selama 10 menit untuk dipanaskan kemudian diamati perubahan yang terjadi (Rahmawati dan Muawanah, 2013).

\section{Analisis Kuantitatif Sakarin}

Timbang 15 gr sampel yang sudah dihomogenkan, masukkan ke dalam corong pisah dengan bantuan $50 \mathrm{~mL}$ akuades, tambahkan $5 \mathrm{~mL} \mathrm{HCl} 3 \mathrm{~N}$. Ekstraksi endapan sakarin dengan larutan kloroform: etanol (9:1) kocok sampai 15 menit. Pisahkan ke dalam Erlenmeyer (lapisan kloroform berada dibagian bawah). Kedalam corong pisah tambahkan $15 \mathrm{~mL}$ kloroform: etanol, kocok lagi dan pisahkkan larutan kloroform, ulangi sekali lagi dengan menambahkan $10 \mathrm{~mL}$ kloroform: etanol. Hasil penyaringan kloroform: etanol masukkan lagi ke dalam corong pisah yang lain, tambahkan $50 \mathrm{~mL}$ akuades kemudian aduk. Pisahkan lapisan kloroform ke dalam Erlenmeyer lalu keringkan di atas pemanas air. Setelah kering tambahkan $50 \mathrm{~mL}$ akuades dan 5 tetes indikator Brom Thymol Blue. Titrasi dengan $\mathrm{NaOH} \quad 0,1 \mathrm{~N}$ hingga terjadi perubahan warna dari kuning menjadi biru. 


$$
\text { Kadar Sakari }=\frac{V X N X 18,32 \times 100 \%}{M g \text { Sampel }}
$$

Keterangan :

$\mathrm{V} \quad$ : Volume titrasi (ml)

$\mathrm{N} \quad$ : Normalitas $\mathrm{NaOH}$

mg : : Berat Sampel

Penyetaraan : 18,32

\section{Analisis Kuantitatif Siklamat}

Pipet sebanyak $25 \mathrm{ml}$ sampel

kedalam Erlenmeyer secara seksama, tambahkan $50 \mathrm{ml}$ air lalu campur kemudian tambahkan $5 \mathrm{ml}$ asam klorida ( $\mathrm{HCl}) 10 \%$,didinginkan dalam wadah berisi es hingga suhu larutan dibawah $15^{\circ} \mathrm{C}$ kemudian ditambahkan 3 tetes Indikator Methyl Blue dan 2 tetes Amoniak. Kemudian dititrasi dalam keadaan dingin dengan natrium nitrit $\left(\mathrm{NaNO}_{2}\right) \quad 0,1$ M. Titik akhir ditandai dengan terjadinya perubahan warna dari biru menjadi hijau.

Kadar Siklamat $=\frac{1000}{V_{s}} X V_{t} X f X 19,83$

Keterangan :

$\begin{array}{ll}\mathrm{Vs} & : \text { Volume sampel } \\ \mathrm{Vt} & : \text { Volume titrasi } \\ \mathrm{f} & : \text { Konsentrasi } \mathrm{NaNO}_{2} \\ \text { Penyetaraan } & : 19,83 \mathrm{mg}\end{array}$

\section{HASIL PENELITIAN}

Dari hasil penelitian Analisis pemanis buatan (Sakarin dan Siklamat) pada minuman teh kemasan botol yang beredar di Minimarket Kota Makassar di Laboratorium Kimia Analisis Makanan dan Minuman Akademi Analis Kesehatan Muhammadiyah Makassar pada tanggal 22-24 Mei 2015 yang menggunakan sampel sebanyak 10 sampel dilakukan secara Purposive Sampling dan diperiksa dengan menggunakan dua metode yaitu Analisa Kualitatif dan Analisa Kuantitatif, maka didapatkan hasil penelitian sebagai berikut:

Tabel 1. Hasil Analisa kualitatif dan kuantitatif pemanis buatan (Sakarin) pada Minuman Teh Kemasan Botol

\begin{tabular}{ccc}
\hline $\begin{array}{c}\text { Jenis } \\
\text { Sampel }\end{array}$ & Hasil & $\begin{array}{c}\text { Kadar } \\
\text { Sakarin } \\
(\%)\end{array}$ \\
\hline A & + & 0.21 \\
B & - & -
\end{tabular}

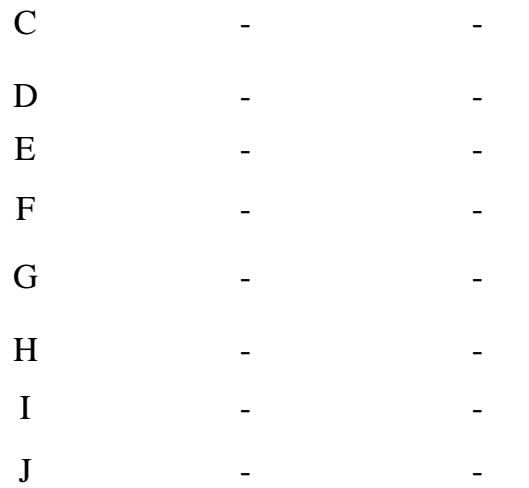

Keterangan : + (positif): mengandung sakarin, - (negatif): tidak mengandung sakarin

Tabel 2.Hasil Analisa kualitatif dan kuantitatif siklamat pada Minuman Teh Kemasan Botol

\begin{tabular}{ccc}
\hline $\begin{array}{c}\text { Jenis } \\
\text { Sampel }\end{array}$ & Hasil & $\begin{array}{c}\text { Kadar } \\
\text { Siklamat } \\
(\mathbf{m g} / \mathbf{K g})\end{array}$ \\
\hline A & + & 359 \\
B & + & 259 \\
C & + & 380 \\
D & + & 375 \\
E & + & 285 \\
F & + & 420 \\
G & - & - \\
H & + & 314 \\
I & + & 295 \\
J & + & 476 \\
\hline
\end{tabular}

Berdasarkan pemeriksaan laboratorium secara kualitatif pada 10 jenis sampel minuman teh kemasan botol yang diambil, ditemukan satu (sampel A) mengandung Sakarin dan sembilan (A, B, C, D, E, F, H, I, J) yang mengandung Siklamat. Sehingga dengan demikian dari 10 sampel terdapat $10 \%$ ( 1 sampel) dan $90 \%$ (9 sampel) yang dinyatakan positif.

\section{PEMBAHASAN}

Dalam analisis kadar pemanis buatan ini sampel yang digunakan adalah beberapa minuman teh kemasan botol yang beredar di minimarket Kota Makassar. Sakarin merupakan garam natrium dari asam sakarin. Pemanis buatan ini mempunyai tingkat kemanisan 200-700 kali gula. Sakarin digunakan sebagai pengganti gula karena mempunyai sifat yang stabil, nilai kalori yang rendah, dan harganya relatif murah, 
selain itu sakarin banyak digunakan untuk mengganti sukrosa bagi penderita diabetes melistus atau untuk bahan pangan yang berkalori rendah.

Penggunaan sakarin dicampur dengan bahan pemanis lain seperti siklamat atau aspartam. Hal itu dimaksudkan untuk menutupi rasa tidak enak dari sakarin dapat memperkuat rasa manis. Sebagai contoh, kombinasi sakarin dan siklamat dengan perbandingan $1: 3$ merupakan campuran yang lebih baik sebagai pemanis yang menyerupai gula dalam minuman.

Siklamat adalah pemanis buatan yang masih populer di Indonesia. Pemanis buatan ini merupakan garam natrium dari asam siklamat. Sifat siklamat sangat mudah larut dalam air dan mempunyai tingkat kemanisan 30 kali gula. Di dalam tubuh, sakarin dan siklamat dalam jumlah yang sedikit dapat membantu penderita diabetes sebagai pangan karena tidak menimbulkan kelebihan gula darah, memenuhi kebutuhan kalori rendah untuk penderita kegemukan. Akan tetapi jika penggunaanya terlalu banyak dan melebihi batas maksimun yang telah ditentukan maka dalam kurun waktu yang lama akan mengakibatkan gangguan kesehatan seperti migrain, tremor, insomnia, sakit kepala, kehilangan daya ingat, alergi, asma, hipertensi, kebotakan, dan dapat menyebabkan kanker otak dan kanker kandung kemih.

Pada penelitian analisis kadar pemanis buatan dalam minuman teh kemasan botol ini menggunakan metode alkalimetri untuk pemeriksaan sakarin dengan terlebih dahulu dilakukan uji kualitatif dengan penambahan K.Na Tartrat 3\% dan reagen Nessler yang akan membentuk endapan kuning kemudian hasil yang positif dilanjutkan dengan uji kuantitatif dengan melakukan standarisasi larutan baku dengan penambahan indikator PP yang kemudian dititrasi sampai timbul warna merah muda.

Setelah standarisasi, dilakukan pemeriksaan kadar sakarin dengan cara dititrasi menggunakan $\mathrm{NaOH} \quad 0,1 \quad \mathrm{~N}$ dengan indikator Brom Thymol Blue yang menghasilkan perubahan warna dari kuning menjadi biru dan metode nitrimetri untuk pemeriksaan siklamat dengan terlebih dahulu melakukan uji kualitatif dengan penambahan $\mathrm{NaNO}_{2}$ $10 \%$ dan $\mathrm{BaCl}_{2} \quad 10 \%$ kemudian dipanaskan yang menghasilkan endapan putih kemudian hasil yang positf dilanjutkan dengan penetapan kadar siklamat yang terlebih dahulu melakukan standarisasi larutan baku dengan penambahan indikator Methyl Blue dan Amoniak yang kemudian dititrasi sampai terjadi perubahan warna dari biru menjadi hijau. Setelah standarisasi dilakukan pemeriksaan kadar siklamat dengan cara penambahan $\mathrm{HCl} 10 \%$ dan Amoniak kemudian dititrasi dengan $\mathrm{NaNO}_{2} 0,1 \mathrm{M}$ menggunakan indikator Methyl Blue yang menghasilkan perubahan warna dari biru menjadi hijau.

Berdasarkan hasil penelitian menggunakan uji kualitatif pada beberapa minuman teh kemasan botol dari 10 sampel, terdapat 1 sampel yang mengandung sakarin yang ditandai dengan terbentuknya endapan kuning dan 9 sampel yang mengandung siklamat yang ditandai dengan terbentuknya endapan putih setelah dipanaskan. Pada hasil penelitian menggunakan uji kuantitatif sakarin diperoleh pada sampel A sebanyak 0,21 \%, sedangkan pada analisis kadar siklamat dari 9 sampel, yang tertinggi pada sampel $\mathrm{J} 476 \mathrm{mg} / \mathrm{kg}$, sampel F $420 \mathrm{mg} / \mathrm{kg}$, sampel C 380 $\mathrm{mg} / \mathrm{kg}$, sampel D $375 \mathrm{mg} / \mathrm{kg}$, sampel A 359, sampel H $314 \mathrm{mg} / \mathrm{kg}$, sampel B 295 $\mathrm{mg} / \mathrm{kg}$, sampel I $295 \mathrm{mg} / \mathrm{kg}$. Sedangkan yang terendah pada sampel E $285 \mathrm{mg} / \mathrm{kg}$.

Endapan kuning yang terbentuk pada pemeriksaan sakarin terjadi karena adanya reaksi antara sampel dengan larutan K.Na Tartrat 3\% dan reagen Nessler dan endapan putih yang terbentuk pada pemeriksaan siklamat karena adanya reaksi antara sampel dengan larutan $\mathrm{NaNO}_{2} \quad 10 \%$ dan $\mathrm{BaCl}_{2}$ 10\%. Adanya perbedaan kadar siklamat yang diperoleh pada setiap sampel tergantung pada volume titran yang diperoleh dan jumlah penambahan siklamat yang digunakan. Penelitian yang dilakukan merupakan penelitian yang bersifat deskriptif yang 
bertujuan untuk mengetahui ada tidaknya pemanis buatan (sakarin dan siklamat) pada minuman teh kemasan botol yang beredar di Kota Makassar serta menentukan kadarnya.

\section{KESIMPULAN}

Dari hasil penelitian Analisis Kadar Pemanis Buatan (Sakarin dan Siklamat) pada Minuman Teh Kemasan Botol yang Beredar di Kota Makassar dengan menggunakan metode Alkalimetri dan Nitrimetri, yang pemeriksaannya dilakukan di Laboratorium Kimia Akademi Analis Kesehatan Muhammadiyah Makassar, dengan menggunakan 10 sampel, 1 sampel mengandung sakarin dan 9 sampel mengandung siklamat. Pada pemeriksaan sakarin diperoleh kadar pada sampel A sebanyak $0,21 \%$ dan pada pemeriksaan siklamat diperoleh hasil yang tertinggi pada sampel J $476 \mathrm{mg} / \mathrm{kg}$, sampel $\mathrm{F}$ sebanyak $420 \mathrm{mg} / \mathrm{kg}$, sampel C 380 $\mathrm{mg} / \mathrm{kg}$, sampel D sebanyak $375 \mathrm{mg} / \mathrm{kg}$, sampel A sebanyak 359, sampel H sebanyak $314 \mathrm{mg} / \mathrm{kg}$, sampel B sebanyak $295 \mathrm{mg} / \mathrm{kg}$, sampel I sebanyak $295 \mathrm{mg} / \mathrm{kg}$. Sedangkan yang terendah pada sampel E $285 \mathrm{mg} / \mathrm{kg}$.

\section{DAFTAR PUSTAKA}

C. Wijaya H, Noryawati M. 2010. Bahan Tambahan Pangan, Pemanis. Bogor: Penerbit IPB Press.

Dewi 2012. Analisa Kandungan Siklamat pada Minuman Siap Saji Yang dijual Belikan di Pasar Sentral kota Makassar (KTI). Makassar: Akademi Analis Kesehatan Muhammadiyah Makassar

Envelyta. 2013. Kimia Analisis (http://.envelyta-appe.com). Diakses tanggal 1 Juni, 2014.

Herawati W. 2013. Teknik Budidaya Tanaman Teh. Jogjakarta: Penerbit Trans Idea Publishing.

Lutony, Tony Luqman. 1993. Tanaman Sumber Pemanis. Jakarta: Penerbit PT Penebar Swadaya.

Rahmawati, Muawanah. 2013. Penuntun Praktikum Kimia Analisis Makanan dan Minuman (KTI). Makassar:
Akademi Analis Kesehatan Muhammadiyah Makassar.

Rahmawati, Muawanah. 2012. Penenuntun Praktikum Kimia Analitik II. Makassar: Akademi Analis Kesehatan Muhammadiyah Makassar. Makassar.

Rohman A, Sumantri. 2013. Analisis Makanan. Yogyakarta: Penerbit Gadjah mada University Press.

Winarno, F.G, 2002. Kimia Pangan Dan Gizi. Jakarta: Penerbit Gramedia Pustaka Utama. 